\title{
The value of 5-aminosalicylic acid in inflammatory bowel disease for patients intolerant or allergic to sulphasalazine
}

\author{
I.P. Donald and S.P. Wilkinson \\ Gloucestershire Royal Hospital, Great Western Road, Gloucester GL1 3NN, UK.
}

\begin{abstract}
Summary: The use of sulphasalazine in inflammatory bowel disease is often limited by intolerance or allergy. In previous studies 5-aminosalicylic acid (5ASA), the active ingredient of sulphasalazine, coated with an acrylic resin, has been shown to be as effective as sulphasalazine in maintaining remission. In this study coated 5ASA was given to 37 patients intolerant or allergic to sulphasalazine. Thirty-three patients have tolerated 5ASA satisfactorily, and most experienced improved control of their disease. Four patients reported similar side effects with sulphasalazine and 5ASA.
\end{abstract}

\section{Introduction}

Sulphasalazine is of established value for maintaining remission in ulcerative colitis (Dissanayake \& Truelove, 1973), and probably in colonic Crohn's disease (Summers et al., 1979). Unfortunately its use is often limited by intolerance or allergy which are thought to be due to sulphapyridine, a component without therapeutic effect. The active component 5aminosalicylic acid (5ASA) (Azad Kahn et al., 1977) is released in the colon as a result of bacterial activity. Unfortunately it is ineffective when given orally because of denaturation by the acidity of the stomach and rapid absorption (Dew et al., 1982). However, it can now be given coated with 'Eudragit $S$ ', an acrylic resin, so that release is delayed until it reaches a $\mathrm{pH}$ of 7 , this occurring in the terminal ileum or caecum (Dew et al., 1982). Indeed, a double-blind trial has shown comparable efficacy of coated 5ASA and sulphasalazine in maintaining remission in ulcerative colitis (Dew et al., 1983b). This report describes our experience with coated 5ASA ('Asacol') in 37 patients with moderately severe ulcerative colitis or colonic Crohn's disease who were unable to take sulphasalazine.

\section{Patients and methods}

The patients comprise 27 with ulcerative colitis (mean age $42 \mathrm{y}$ ) in 10 of whom this was total, 11 had left-sided disease, and in 6 it was confined to the rectum. The other 10 had Crohn's disease (mean age $40 \mathrm{y}$ ) which was confined to the colon and/or rectum. All patients had either suffered a severe relapse in the 6 months

Correspondence: S.P. Wilkinson, M.D., F.R.C.P.

Accepted: 2 July 1985 prior to starting 5ASA, or had poorly controlled disease at the start of the treatment.

Sulphasalazine had been withdrawn because of rashes (14), nausea and headache (7), headache alone (8), nausea alone (4), abdominal pain (2), general malaise (1) and poor anti-coagulant control (1). Those intolerant to sulphasalazine were unable to take even $1 \mathrm{~g} / \mathrm{d}$. A dose of $800 \mathrm{mg} / \mathrm{d}$ of 5ASA ('Asacol') was initially given, which is equivalent to $2 \mathrm{~g}$ of sulphasalazine (Dew et al., 1983b). This dose was later increased in 16 patients because of poor disease control. When tolerated, treatment has been given for 3-24 months (mean 13.1).

\section{Results}

Seven patients reported side effects, in two cases multiple, attributed to 5ASA. These were headaches (4), nausea (3) and abdominal pain (2). Four of these patients stopped taking 5ASA as a result. Two patients experienced headaches on $1600 \mathrm{mg} / \mathrm{d}$, and were free of headaches at a reduced dose. Four patients ( 3 with headaches and 1 with abdominal pain) had reported similar side effects with sulphasalazine. Four other patients have stopped 5ASA, because of non-compliance (1), a severe relapse (1), and following panproctocolectomy for continuing severe disease (2). The patient with unstable anti-coagulant control on sulphasalazine has experienced much improved control on 5ASA.

Seventeen of the patients with ulcerative colitis were in remission when starting 5ASA and have been followed for 209 treatment months (mean 12.3). Six suffered a relapse during the first 6 months of treatment giving a relapse rate of $35 \%$ per 6 treatment 
months, and one patient had a relapse at 9 months. Eight patients have had a year free of disease during treatment. It had been difficult to maintain remission without corticosteroids in the ten patients whose ulcerative colitis had been active when starting 5ASA. They have been followed for 123 treatment months (mean 12.3). In 7 disease activity has declined since starting 5ASA, with complete sigmoidoscopic remission in 5. Three patients have been able to stop corticosteroids without an immediate relapse, while a further patient has had a substantial reduction in steroid therapy.

Of the patients with Crohn's colitis, 4 of 7 with poor disease control when starting 5ASA have achieved a remission during the first 6 months of treatment. All 3 patients in remission on starting 5ASA have remained in remission during the first year of treatment.

Blood samples were taken both before starting 5ASA and at the time of this review for full blood count and multi-channel biochemical screening. No abnormality unrelated to the disease was discovered.

\section{Discussion}

5ASA with an acrylic resin coating would appear to be a suitable alternative to sulphasalazine, with 33 out of 37 patients intolerant or allergic to sulphasalazine able to take 5ASA. The relapse rate of ulcerative colitis in an unselected group of patients is over $50 \%$ in 6 months (Dissanayake \& Truelove, 1973) while sulphasalazine in a dose of $2 \mathrm{~g}$ /day has been shown to reduce this to around 14\% (Azad Kahn et al., 1980).

\section{References}

AUSTIN, C.A., CANN, P.A., JONES, T.H. \& HOLDSWORTH, C.D. (1984). Exacerbation of diarrhoea and pain in patients treated with 5ASA for ulcerative colitis. Lancet, i, 917.

AZAD KAHN, A.K., HOWES, D.T., PIRIS, J. \& TRUELOVE, S.C. (1980). Optimum dose of sulphasalazine for maintenance treatment in ulcerative colitis. Gut, 21, 232.

AZAD KAHN, A.K., PIRIS, J. \& TRUELOVE, S.C. (1977). An experiment to determine the active therapeutic moiety of sulphasalazine. Lancet, ii, 892.

DEW, M.J., HARRIES, A.D., EVANS, B.K. \& RHODES, J. (1983a). Treatment of ulcerative colitis with oral 5-aminosalicylic acid in patients unable to take sulphasalazine. Lancet, ii, 801.

DEW, M.J., HARRIES, A.D., EVANS, N., EVANS, B.K. \& RHODES, J. (1983b). Maintenance of remission in
The apparently high relapse rate of $35 \%$ in 6 months in the present series would at first seem unacceptable. However, these are highly selected patients both by $c$ virtue of intolerance or allergy to sulphasalazine and having severe colitis requiring therapy because of poor disease control or frequent relapses. As already pointed out coated 5ASA has been shown to be as effective as sulphasalazine in maintaining remission in unselected patients with ulcerative colitis (Dew et al., 1983b). Higher doses of sulphasalazine achieve a lower relapse on rate (Azad Kahn et al., 1980) and this may also be the case with 5ASA. In this study the maintenance of remission without steroid therapy achieved in 10 out of 17 patients who had poor disease control at the start of treatment was very encouraging. An improved sense of well-being was commented on by many patients during 5ASA treatment.

It is emphasized that a small proportion of patients will develop side effects on 5ASA, in particular : headache, similar to when taking sulphasalazine. Thus headache would appear not necessarily to be due to the sulphapyridine component of sulphasalazine. In 은 previous reports 3 out of 35 patients (Dew et al.,1983a) and 2 out of 15 (Austin et al., 1984) developed similar side effects on both drugs.

\section{Acknowledgements}

Asacol was supplied by Tillotts Laboratories, Henlow, Bedfordshire, UK.

ulcerative colitis with 5-aminosalicylic acid in high doses by mouth. British Medical Journal, 287, 23.

DEW, M.J., HUGHES, P.H., LEE, M.G., EVANS, B.K. \& RHODES, J. (1982). An oral preparation to release drugs in the human colon. British Journal of Clinical Pharmacology, $14,405$.

DISSANAYAKE, A.S. \& TRUELOVE, S.C. (1973). A controlled therapeutic trial of long-term maintenance treatment of ulcerative colitis with sulphasalazine (Salazopyrin). Gut, $14,923$.

SUMMERS, R.W., SWITZ, D.M., SESSIONS, J.T. JR., BECKTEL, J.M., BEST, W.R., KERN, F. JR. \& SINGLETON, J.W. (1979). National cooperative Crohn's disease study: results of drug treatment. Gastroenterology, 77, 847. 